\title{
OS DEPÓSITOS DE MOVIMENTOS DE MASSA SUBMARINOS DAS BACIAS MARGINAIS DO SUDESTE BRASILEIRO: TIPOS, OCORRÊNCIAS, IDADES E FEIÇÕES DIAGNÓSTICAS
}

\author{
Cízia Mara Hercos (CENPES/PDIEP/GMG)
}

Copyright 2021, SBGf - Sociedade Brasileira de Geofísica.

This paper was prepared for presentation during the $17^{\text {th }}$ International Congress of the Brazilian Geophysical Society held in Rio de Janeiro, Brazil, 8-11 November 2021.

Contents of this paper were reviewed by the Technical Committee of the $17^{\text {th }}$ International Congress of the Brazilian Geophysical Society and do not necessarily represent any position of the SBGf, its officers or members. Electronic reproduction or storage of any part of this paper for commercial purposes without the written consent of the Brazilian Geophysical Society is prohibited.

\section{Resumo}

Os depósitos de movimentos de massa (DMM) representam parte importante do registro geológico desde o Cretáceo até o Quaternário das bacias marginais do sudeste brasileiro. Esses depósitos têm sua origem controlada pelas forças gravitacionais que tendem a mover os solos/rochas para baixo (Os produtos de fluxos gravitacionais turbulentos não serão abordados neste trabalho).

A extensa cobertura areal com dados sísmicos 3D dessas bacias propiciou o reconhecimento, mapeamento, classificação e a construção de modelos deposicionais conceituais. Adicionalmente, dados de testemunhos do fundo marinho e dados de poços e testemunhos de rochas permitiram a datação dos eventos geradores. Como este tipo de evento pode mobilizar/depositar sedimentos/rochas de várias idades, a datação dos depósitos é feita de modo indireto, datando-se amostras de sedimentos/rochas basais e de cobertura.

De modo geral, os DMM são classificados através da sua estrutura interna e reologia de fluxo. Os depósitos de movimentos de massa identificados em águas profundas das bacias marginais do Sudeste são principalmente de três tipos: depósitos de fluxos de detritos (debritos), depósitos de escorregamento (slumps) e depósitos de deslizamentos (Slides). Grande parte destes depósitos possui composição predominantemente lamosa, e por isso apresenta amplitude sísmica semelhante às amplitudes dos demais depósitos lamosos (contornitos e hemipelagitos). Porém, de modo distinto, as sismofácies relacionadas ao arranjo das reflexões internas dos DMM é caótica ou, no caso de depósitos muito desintegrativos, free. Nos debritos predominam clastos de variados tamanhos imersos em matriz desintegrada, já os slumps se caracterizam pela presença de dobras e falhas, e nos slides é possível identificar o bloco transladado sobre uma superfície de deslizamento. Em geral, na sísmica, os DMM apresentam superfície de descolamento basal bem-marcada e os topos rugosos.

A maioria dos DMM está posicionada nos taludes médio e inferior e no platô de São Paulo das bacias de Santos, Campos e Espírito Santo, formando um avental de detritos no pé do talude que se coalescem com as línguas de detritos provenientes das desembocaduras dos cânions. Também são observadas cicatrizes e seus depósitos associados em encostas/pé de diápiros e muralhas de sal presentes no Platô de São Paulo, bem como em flancos de calhas estruturais.

É comum a ocorrência de depósitos de movimentos de massa intercalados a sucessões compostas por depósitos turbidíticos e hemipelágicos, sugerindo um controle associado a variações relativas do nível de base. No período das glaciações pleistocênicas, por exemplo, ocorreram quedas expressivas do nível do mar (Regressão forçada). Durante os estágios iniciais da regressão, condicionados pelo reajuste do perfil de equilíbrio do talude, que provavelmente conduziu ao aumento da pressão de poros e possível dissociação de hidratos de gás, ocorreram significativos colapsos retrativos.

Parte dos expressivos DMM miocênicos presentes nas 3 bacias podem ter sua origem associada aos eventos de reativações tectônicas experimentados pela margem sudeste desde o Neógeno ao Quaternário, Tais eventos, em geral, são acompanhados por um aumento da quantidade e recorrência de sismos, os quais ocasionam o aumento da pressão de poros e a degradação cíclica da resistência dos solos, contribuindo para o disparo de movimentos de massa. 